\title{
Educational Framework of Product Lifecycle Management Issues for Master and PhD Study Programmes
}

\author{
Milan Edl \\ University of West Bohemia, Faculty of Mechanical Engineering, \\ Department of Industrial Engineering and Management, Czech Republic \\ edl@kpv.zcu.cz
}

\begin{abstract}
This article focuses on the description and implementation of PLM in the education of students at the University of West Bohemia. The concept is designed to be deployed in both Master's and $\mathrm{PhD}$ study programs. It is also used for training research workers in universities and industrial enterprises in the Czech Republic. The entire educational framework is developed in accordance with sustainable management of the product in its entire life cycle.
\end{abstract}

Keywords: PLM, sustainable product, educational framework, factory as product, sustainable production system.

\section{$1 \quad$ Introduction}

At the outset something should be said about the current state of education in industrial engineering at the University of West Bohemia in Pilsen (UWB). Industrial engineering has an almost 20-year tradition at the University provided by the Department of Industrial Engineering and Management at the Faculty of Mechanical Engineering. The Department has much experience in education and applied research, and also cooperation with industrial partners. In terms of education, it is important to stress that the Department has accreditation for Bachelor, Master and PhD study in the field of industrial engineering and management.

It is precisely this background that has been used to create and improve the educational framework for students at all stages of their education in the field of industrial engineering and Product Lifecycle Management. The three fundamental tenets of the new educational framework are three projects undertaken with assistance from the European Union Structural Fund and the Czech Ministry of Education, Youth and Sports.

It is also important to add that the creation of this educational framework would not have been possible without the experience gained from foreign workplaces.

\section{Motivation}

It is necessary to look at product management from different viewpoints. Not just from a technical perspective, not only from a technical point of view, but we must also add other views. Important factors which are necessary to include are: 
- Reducing the time (maybe timing) of release of product on to the market

- Orientation towards product quality

- Teamwork

- Modularity of product (meta-product)

- Knowledge based approach

- Not undervaluing the second half of the product lifecycle

- Etc...

These conditions should be considered as smart products and intelligent manufacturing systems. What are 'smart products' and 'intelligent manufacturing systems'? It does not mean anything other than the integration of different approaches, tools, ideas, resources, etc., into the final product. Final product can be regarded as the production system, for example, meta-product.

A production system [1] can no longer be seen as the view of F. W. Taylor: Taylorism can be described as: the direction where management methods and means are used that were created and defined in the early 20th century in the USA by F. W. Taylor. Time studies of workers determined that daily tasks were based on the most powerful performances of workers, without taking into account the possibilities and abilities of the average man. Taylorism was based on the idea of homo oeconomicus, who is motivated to work exclusively for material benefits and, as an "isolated individual" willing to submit to a strict, standardized mode of operation.

The production system must be understood as an integral system where it is necessary to apply the elements of intelligence. It is both product development and a combination of all the parts of the product lifecycle.

The following statement [2] was made by Prof. van Brussel from Katholieke Universiteit in Leuven:

\section{Products and Production Systems Should Be 'Tailor Made' Not 'Taylor Made'!}

The basic idea is clear. It is necessary to satisfy the customer. Modular product is quite advantageous for the efficiency of the product development (if it works).

The production system must be understood as a product, so the modular production system is very important for creating a modular product.

And it is exactly this point of view which is key for industrial engineering education at the University of West Bohemia, and the entire framework of this study programme is based on and gradually modified according to two basic principles. The first is industrial strategy in a Czech and European environment which is based on directives formulated with the support of the Strategic Research Agenda and/or at the Czech governmental level. The second principle is the formulation of the requirements of representatives of Czech industry. These are representatives from companies of various sizes and from varying fields. Feedback from the Czech Technology Engineering Platform (members of Manufuture) was also used. 


\section{Roles of Universities}

But it is also essential to look at education in a broader context. What is the role of the University of West Bohemia? The University of West Bohemia in Pilsen has educational, research and application roles. These three pillars are also a source of financing. Education is usually financed by the Ministry of Education. Projects in the field of research, development and innovation are usually financed from the state budget, EU funds and industrial practice. And then there are the financial resources from industrial practice to solve specific industrial problems.

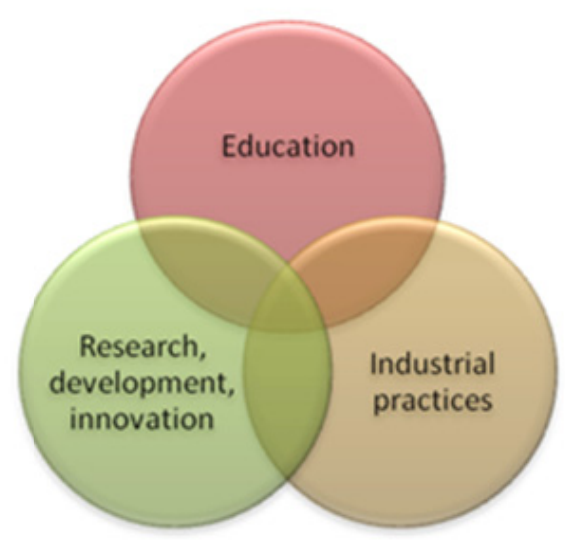

Fig. 1. Roles of universities

At the present time, the Department of Industrial Engineering and Management is working on several projects. The first is "Product life cycle in a digital factory environment", the second is "Quality research team focused on the issues of product lifecycle management" and the third is "Creating and enhancing partnerships between universities and practice".

\section{Proposal and Implementation of an Educational Framework}

Based on the identified (or verified) facts, there have been modifications to study programmes both at master's level and also at PhD level. It should be noted that our university students have found employment in industry (industrial plants) and research organizations. There is a need to develop programmes with short to medium term impacts on industry. Therefore, modifications have been made to Master and $\mathrm{PhD}$ study programs.

It is also necessary to highlight the cooperation with the following foreign institutions in the creation of an educational framework for PLM at UWB: 
- University of Žilina (SK)

- Technical University of Košice (SK)

- University of Zielona Góra (PL)

- University of Bielsko-Biala (PL)

- University of Maribor (SI)

- Fraunhofer-Institut für Fabrikbetrieb und -automatisierung IFF Magdeburg (DE)

- Technical University of Chemnitz (DE)

- Czech Liaison Office for Research and Development (BE)

- SIRRIS (BE)

- Manchester Metropolitan University (GB)

\subsection{Product Lifecycle in Digital Factory Environment}

The project for innovating the Industrial Engineering masters study program is called "Product life cycle in the digital factory environment" [7]. The objective of the project is to innovate the teaching programmes of Bachelor and Master Degree students at the Faculty of Mechanical Engineering at the University of West Bohemia in Pilsen. It will be implemented by the creation of 19 e-learning multimedia modular courses, which will be upgraded to existing programmes. The target group is mainly students with a diverse range of knowledge acquired in the studied subjects (design, technology, production, etc.). Course modules will be used in 38 subjects in six Bachelor's and Master's Degree programmes at three faculties.

Modules developed within the project are as follows:

- Theoretical and System approach for Product Lifecycle Management (PLM) in Digital Factory environment (DF)

- Digital company

- System approach to life cycle engineering design in DF environment

- Legal aspects in connection with the life cycle of the product

- Virtual reality in DF environments

- Knowledge management and innovation

- Performance management processes and increase value-added product in the DF environment

- Technological preparation and support for production in DF environment

- Design of investment units

- Design of material handling

- NC Technology

- Design of production systems (processes) in DF environment

- Design of production bases

- Creation and optimization of workplaces

- Analysis, modelling and optimization

- Logistics

- Simulation of manufacturing systems and processes

- Planning and control production and information support in DF environment

- Methods of Industrial Engineering

- Production planning 
- Integrated management systems and their applications in manufacturing

- Algorithms and their computer support

- Economic analysis and evaluation of production processes and products

These modules are currently implemented in the study programme of Industrial Engineering and Management at the Faculty of Mechanical Engineering, UWB.

\subsection{Highly Professional Research Team Focused on Product Lifecycle Management and Digital Factory}

The project for innovating the Industrial Engineering $\mathrm{PhD}$ study programme is called "Highly professional research team focused on the topic of Product Lifecycle Management and Digital Factory" [6]. The basic idea of the project is to improve, streamline and support using specialist knowledge the work of the research centres on the issues of Product Lifecycle Management environment in the Digital Factory at the Faculty of Mechanical Engineering, University of West Bohemia in Pilsen. The project creates specific training modules for acquiring knowledge and skills of researchers and their use in effective research teamwork on the topic. Its character is interdisciplinary and it will be therefore resolved in integrated interdisciplinary research in the fields of design, technology and industrial engineering, which will interconnect into one research team for solving problems using methods and tools of digital business. Furthermore, the cooperation of the team with foreign research teams will be prepared as a necessary condition of quality and sustainability of the research.

In order to fulfil other objectives:

- four industry-oriented research groups at the faculty will be integrated within one multidisciplinary research team,

- the materials for training researchers and doctoral students in this field will be elaborated,

- cooperation of teams with renowned international research centres will be prepared.

Knowledge of individual topics from the field of digital companies based on the use of information technology (CAD, CAM, CAP, ERP, etc.) has a strong tradition at the Faculty of Mechanical Engineering, in the fields of design, technology and industrial engineering (mainly represented by three departments and one research centre). The research of particular topics is currently separated into four research groups that do not cooperate effectively. Therefore, the disconnected research group from the fields of design, technology and industrial engineering will be integrated into an interdisciplinary research team in order to improve and streamline the management team, based on synergies, and to improve performance in solving common problems of digital research companies. These results in the NUTS II Southwest unique research facility focus on training researchers to develop research and practical application of innovations in the issues of the digital enterprise. This method of ensuring the discussed issue is in conformity with the solution originating from foreign research institutions dealing with the concept of digital enterprise. 
The research team will consist of academic staff, PhD students and selected students of various disciplines at the Faculty of Mechanical Engineering, along with researchers from industrial companies.

Modules that are being developed within the project are as follows:

- Digital company (DP)

- Product lifecycle management (PLM)

- Enterprise Information Systems and DP

- Knowledge management and DP

- Artificial Intelligence and DP

- Virtual reality and DP

- CAx and DP

- Control via data management and PLM and DP

- Reverse engineering and DP

- Design of production systems and DP

- Assembly, robots and DP

- NC Technology and DP

- Design of production processes and DP

- Logistics and DP

- Production Planning and Control and DP

- Modelling and simulation, and DP

- Evaluation of the performance in the company and DP

The following figure (Fig.2) shows a matrix of relations between individual modules, where value 1 means a weak but existing relationship, 2 means a strong relationship and 3 indicates a very strong relationship.

\begin{tabular}{|c|c|c|c|c|c|c|c|c|c|c|c|c|c|c|c|c|c|}
\hline & 1. & 2. & 3. & 4. & 5. & 6. & 7. & 8. & 9. & 10. & 11. & 12. & 13. & 14. & 15. & 16. & 17. \\
\hline 1) Digital company (DP) & - & 3 & 3 & 2 & 2 & 3 & 2 & 3 & 3 & 3 & 3 & 3 & 3 & 3 & 3 & 3 & 3 \\
\hline 3) Enterprise Information Systems and DP & & & - & & & & 2 & 2 & 1 & 1 & 1 & 2 & 2 & 1 & 2 & 2 & \\
\hline 5) Artificial Intelligence and DP & & & & & $\cdot$ & 1 & 1 & & 1 & 1 & & & & & 1 & & 1 \\
\hline 6) Virtual reality and DP & & & & & & - & & & 3 & 2 & 3 & 3 & 3 & 2 & & 2 & 2 \\
\hline 7) Evaluation of the performance in the company and DP & & & & & & & - & & & 2 & 1 & & 2 & 2 & 2 & 2 & \\
\hline 8) Control via data management and PLM and DP & & & & & & & & - & 3 & 2 & 2 & 2 & 3 & 2 & 2 & 2 & \\
\hline 11) Assembly, robots and DP & & & & & & & & & & & $\cdot$ & 1 & 3 & 1 & 1 & 2 & \\
\hline 12) NC Technology and DP & & & & & & & & & & & & - & 3. & & 1 & 1 & \\
\hline 13) Design of production processes and DP & & & & & & & & & & & & & - & 1 & 2 & 2 & 1 \\
\hline 14) Logistics and DP & & & & & & & & & & & & & & - & 2 & 2 & \\
\hline 15) Production Planning and Control and DP & & & & & & & & & & & & & & & - & 2 & \\
\hline 16) Modeling and simulation, and DP & & & & & & & & & & & & & & & & - & \\
\hline
\end{tabular}

Fig. 2. Relationship matrix

The whole concept is conceived as a means for designing modules to create a methodical, logical approach to creating products, from the initial idea through design and production to retail and maintenance and disposal. These modules can be called 'sequential'. However, in order to 'function' these modules need further essential activities which are described in other types of modules. These are called 'profile' modules. 
As can be seen from the matrix, all connecting elements are already in the modules, which cover all the other implemented project modules. Other key modules (in terms of connectivity with other thematic units) are Virtual Reality and Planning Manufacturing Processes.

All the modules presented here are included as courses for students of all $\mathrm{PhD}$ study areas at the Faculty of Mechanical Engineering, UWB.

\subsection{Creating and Enhancing Partnerships between Universities and Practice}

Improving study programmes is an important step, but it is not the only necessary step that needs to be made. There must be greater interaction with industry and the European Research Area. To this end UWB is also working on the project "Creating and Enhancing Partnerships between Universities and Practice" [8]. This project is aimed at expanding the contacts and cooperation between universities and private and public sectors in order to contribute to the improvement of the design of a competitive workforce. Such cooperation will be mutually beneficial - students will bring into practice the theoretical knowledge of the new organization and a fresh perspective to problem solving, while practitioners will apply their experience in teaching. The development of cooperation and professional skills will also contribute to the conference, interactive workshops and the winter school. The project will be supported by international practice and internships, and participation of foreign experts in interactive workshops, which will not only improve the professional and language skills of the people involved, but also increase international cooperation (joint projects, $\mathrm{R} \& \mathrm{D}$ ).

\section{Conclusion}

In conclusion it can be said that positive feedback, especially from companies, is growing stronger over time, and the correctness of moving towards sustainable production systems can be seen. And this is only the beginning of innovation that has not only a technical character, but especially a social dimension.

Acknowledgements. In conclusion, we would like to express our thanks for the support of the projects CZ.1.07/2.2.00/15.0397 "Product Lifecycle in Digital Factory Environment", CZ.1.07/2.3.00/09.0163 "Highly professional research team focused on the topic of Product Lifecycle Management and Digital Factory" and CZ.1.07/2.4.00/17.0054 "Creating and Enhancing Partnerships between Universities and Practice" dealt with in the Operational Program Education for Competitiveness.

Special thanks are due to our foreign partners who participated in consultations for the creation of a system for education of PLM at the University of West Bohemia in Pilsen. 


\section{References}

1. Edl, M., Kurkin, O.: Innovations Information Management Systems: Product Lifecycle Management. Zielona Góra: Wydawnictwo Instytutu Informatyki i Zarzadzanie Produkcja Uniwesytetu Zielonogórskiego, s. 30-s. 43 (2011) ISBN 978-83-933843-0-3

2. Edl, M.: Řízení životního cyklu produktu (PLM). SmartMotion, Plzeň (2012) ISBN 978-80-87539-04-0

3. Sääksvuori, A., Immonen, A.: Product lifecycle management. 3rd edn., vol. xiii, 253 p. Springer (2008) ISBN 978-354-0781-738

4. Tolio, T.: Design of flexible production systems: Methodologies and tools, vol. xiv, $299 \mathrm{p}$. Springer, Berlin (2009c) ISBN 35-408-5414-2

5. Stark, J.: Product lifecycle management: 21 st century paradigm for product realisation, 2nd edn., vol. xxii, 561 p. Springer, New York (2011) ISBN 08-572-9545-4

6. Product Lifecycle in Digital Factory Environment (2009), http: / / www . zivdig. zcu.cz (cit. January 05, 2012)

7. Highly professional research team focused on the topic of Product Lifecycle Management and Digital Factory (2009), http: / /www . vyztymdp. zcu . cz (cit. January 05, 2012)

8. Creating and Enhancing Partnerships between Universities and Practice (2009), http: / /www. unipranet. zcu.cz (cit. January 05, 2012) 